\title{
Underwater Multiple Objects Detection and Tracking using Multibeam and Side Scan Sonar
}

\author{
Henry M. Manik \\ Department of Marine Science \\ and Technology Faculty of \\ Fisheries and Marine Sciences \\ Bogor Agricultural University \\ Kampus IPB Darmaga Bogor \\ Indonesia
}

\author{
Djoko Hartoyo \\ Agency for Assessment and \\ Application Technology (BPPT) \\ Indonesia
}

\author{
Saifur Rohman \\ Marine Technology Program \\ Bogor Agricultural University \\ Kampus IPB Darmaga Bogor \\ Indonesia
}

\begin{abstract}
The objectives of this research is to find out underwater information such as water depth and position of the underwater target using Multibeam and Side Scan Sonar instruments. These instruments are hydroacoustic instrument capable for detecting bathymetry and determine the condition of the sea bottom. In this survey, the data acquisitions are conducted by using a Multibeam Reson Hydrobat and Side Scan Sonar EdgeTech 4200. Bathymetric data were processed using PDS 2000 and a Caris HIPS \& SIPS 6.1 software. Side Scan Sonar Data were processed with SonarWeb and a Caris HIPS \& SIPS 6.1 software. The results of the research are bathymetry map with depths ranging from 4.07 meters to 58.15 meters and found the multiple objects such as targetshaped box or square, strap-shaped targets, target-shaped small bumps, and target objects strapped. The mosaics of acoustic wave reflection intensity were resulted from the sea bottom and have been obtained the estimation value of the highest amplitude from the target shape of frame bridge is $7200-7974 \mathrm{mV}$ and the lowest of the bottom substrate is 258 $454 \mathrm{mV}$.
\end{abstract}

\section{Keywords}

multibeam sonar, side scan sonar, bathymetry, multiple objects, detection, tracking

\section{INTRODUCTION}

Sonar used sound to detect or find objects that are specifically located in the sea [1]. Multibeam Sonar is an acoustic instrument that has the ability to perform three-dimensional mapping of the ocean floor [2]. The water depth measurement using multibeam instrument are fast and has a high accuracy, where this can not be done by a single beam echosounder. In addition to the instrument's ability to perform basic scanning the seawater with very high accuracy and coverage [3] are also able to produce information in the form of backscattering values which can be used to determine the distribution of seafloor sediment type [4].

Besides, side scan sonar instrument was used in the marine survey instrument to conduct seabed imaging [5]. Side Scan Sonar (SSS) is a developed to capable sonar image shows the two-dimensional surface with the contour of the seabed, topography, and the target simultaneously. This instrument is able to distinguish large and small particles making the sea floor such as rocks, mud, sand, gravel, or basic types other waters [6]. SSS is used for various applications, such as detecting the presence of pipelines and submarine cables, the detection of shallow seafloor structure, implementation of dredging, environmental studies, military history, archeology, fisheries, and mining.

The objectives of this research are to measure seawater depth and detection of underwater target using multibeam and side scan sonar respectively.

\section{RESEARCH METHODOLOGY}

\subsection{Time and Location}

This research was carried out for 5 months, from March until July 2012. Data used are raw data from Agency for the Assessment and Application of Technology (BPPT). Data acquisition using Reson Multibeam and Side Scan Sonar Hydrobat Edgetech 4200 conducted on November 29 to December 8, 2011, located in the Kutai in East Kalimantan, which is at approximately the Mahakam River Bridge. Data processing is carried out in the Laboratory of Marine Acoustics and Instrumentation Department of Marine Sciences and Technology, Faculty of Fisheries and Marine Sciences Bogor Agricultural University (IPB) and Laboratory of Technology Center for Marine Survey, Agency for the Assessment and Application of Technology (BPPT), Jakarta. Figure 1 and 2 are a map of the location of the research and tracking of ship.

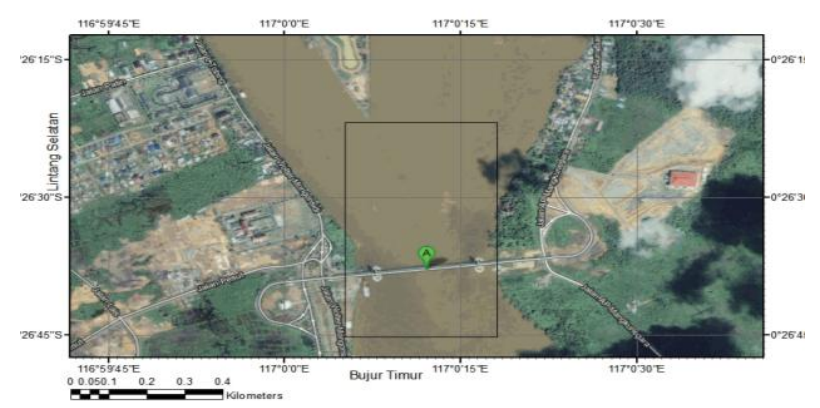

Figure 1. Research Location 


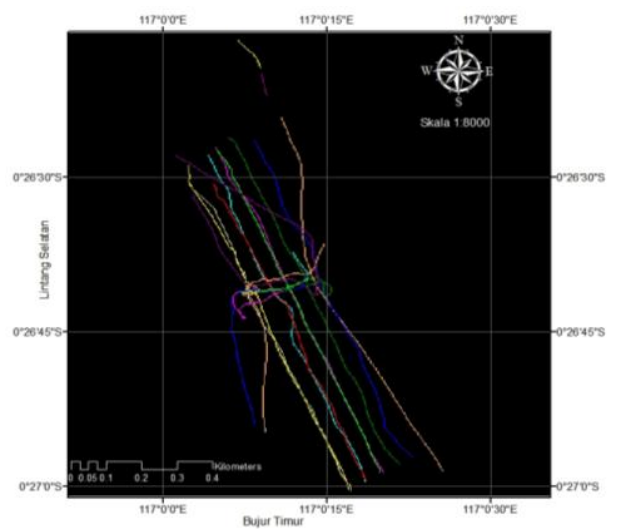

Figure 2. Research vessel tracking

\subsection{Data Acquisition for Multibeam and Side Scan Sonar} Sonar data is corrected for the movement of the ship such as pitch, heave, roll and heading. The correction is done using attitude sensors and positioning CodaOctopus F 180. Multibeam data acquisition was performed using PDS software 2000 with a transducer connected to a monitor [7]. Side Scan Sonar transducer connected to the portable hardware, interface and displays with a laptop using operating system of Windows XP Pro. SSS has a low frequency of 100 and 300 kilohertz and high frequency with 400,600, and 900 kilohertz and can be operated to detect up to a depth of 2,000 meters. Low frequency to detect objects the size of at least 2.5 meters. The high frequency could monitor the body size of 0.5 meters. While the multibeam reson hydrobat frequency 160 $\mathrm{kHz}$ and has 112 beam with a maximum coverage of 200 meters [8].

Sound speed data retrieval measured using Sound Velocity Profile (SVP). Sound velocity data obtained is useful for acoustic data correction. This is because the sound waves are a major factor in the measurement of the depth using underwater instrument.

\subsection{Data Processing for Multibeam}

Multibeam data obtained and processed by using Caris HIPS and SIPS 6.1 shown in Figure 3.

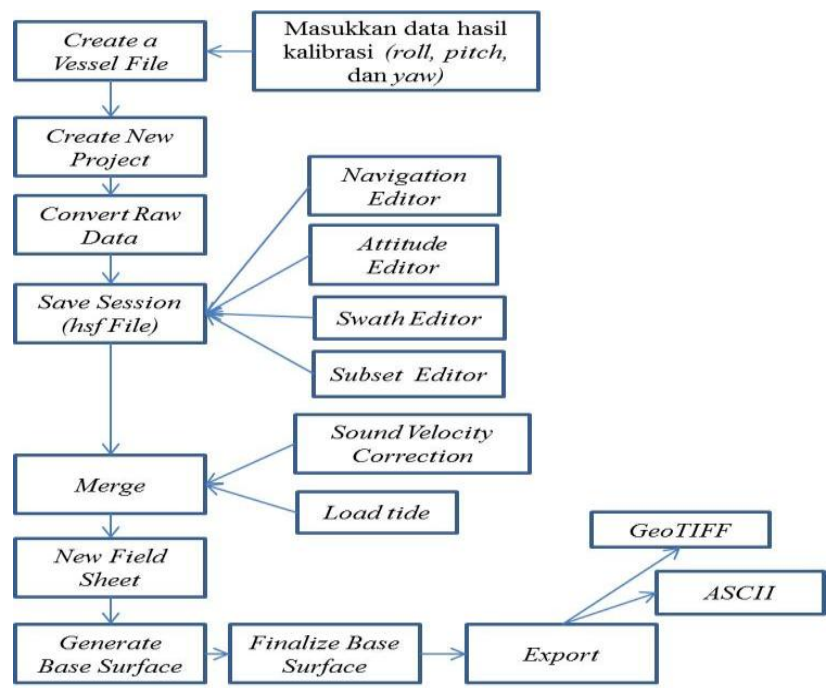

Figure 3. Data processing of Multibeam

\subsection{Data processing for Side Scan Sonar}

Data side scan sonar is obtained in the form of *. XTF and then processed using Caris HIPS and SIPS 6.1 software (Figure 4) in order to obtain target image.

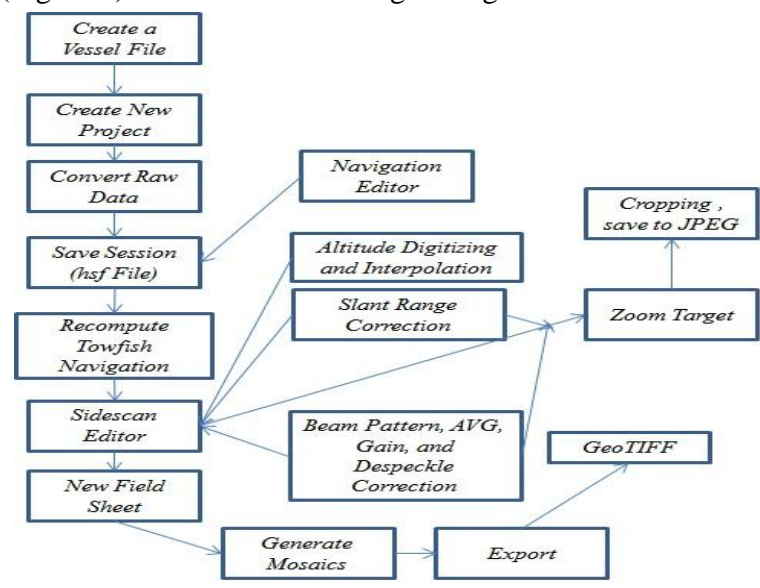

Figure 4. Data processing of SSS

\section{RESULTS AND DISCUSSION}

Sound velocity profile at this sites measured to reduce the effect of errors on the data when using multibeam sounding. During the measurement, the SVP at the sites showed an increase with increasing depth (Figure 5). The $\mathrm{x}$-axis in the figure is the propagation of acoustic waves while the y-axis is the depth measurement.

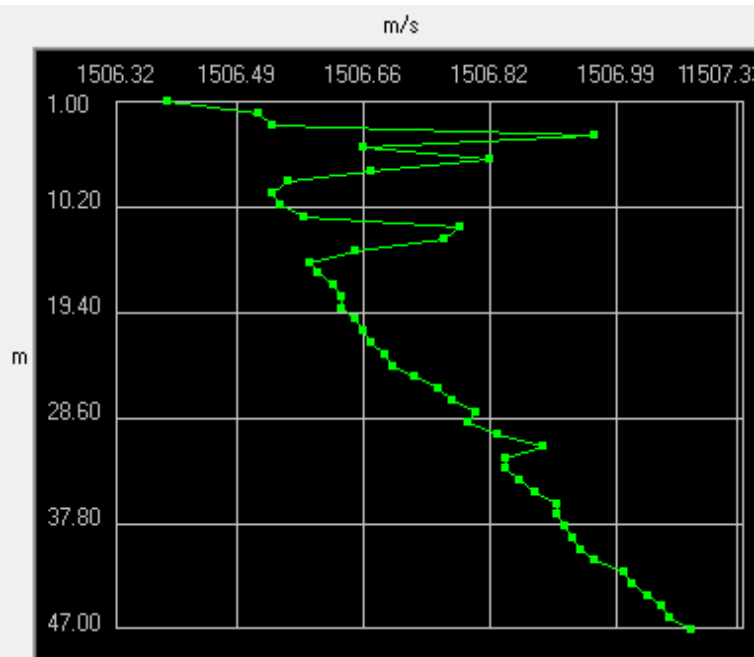

Figure 5. Sound velocity profile

SVP measurement showed the lowest sound velocity occurs at a depth of 1 meter, that is equal to $1506.4 \mathrm{~m} / \mathrm{s}$ and the highest sound speed of $1507.1 \mathrm{~m} / \mathrm{s}$ occurred at a depth of 47 meters and there are fluctuations in the value of the speed of sound at a depth of 3 meters to 15 meters . In general, the value of the propagation of acoustic waves at the study site has a smaller value when compared with the sea surface.

The speed of sound waves in the sea water is influenced by three factors including temperature, salinity, and pressure [9]. SVP at study sites included in the surface region of the layer. Surface is a very varied with depths ranging from 0 to 100 meters [9], so that the increase in temperature will increase the propagation of acoustic waves SVP in the surface layer 
region is strongly influenced by the diurnal changes of water daily and local changes such as heating, cooling, and wind movement [10]. Heat from the sun causes the upper layers of the water is warmer than the bottom. These conditions led to the formation of the mixed layer continues until late afternoon until the gradient becomes negative SVP.

Multibeam data processing resulted 2-dimensional of depth measurement (Figure 6).

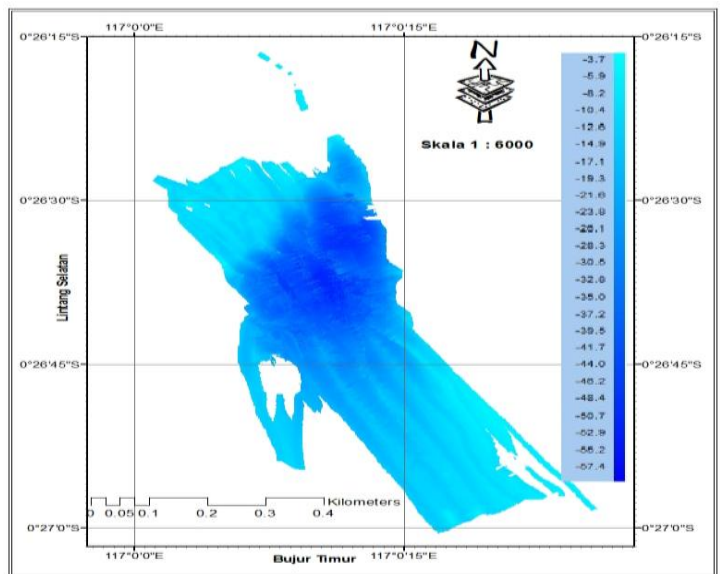

Figure 6. Depth measurement using multibeam

In Figure 6, we explain that the basic topographic survey is formed in the center of the basin, with the highest depth of the basin area is 58.15 meters and has the lowest depth of 4.18 meters. The figure above can be shown that the appearance of blue color gradations, the higher of blue gradation is followed by higher depth. The position of underwater targets detected and mosaic of side scan sonar are shown in Figure 7 and 8, respectively.

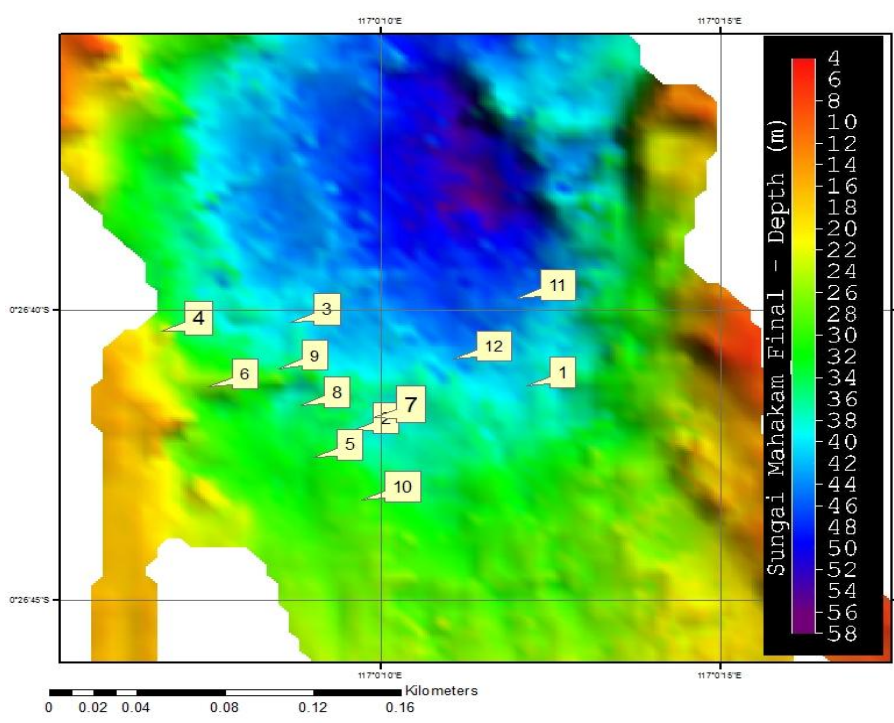

Figure 7. Position of detected underwater target

Figure 9 shows the various underwater target detected by SSS. This image showed multiple objects such as the frame bridge, rope, and other identified target.

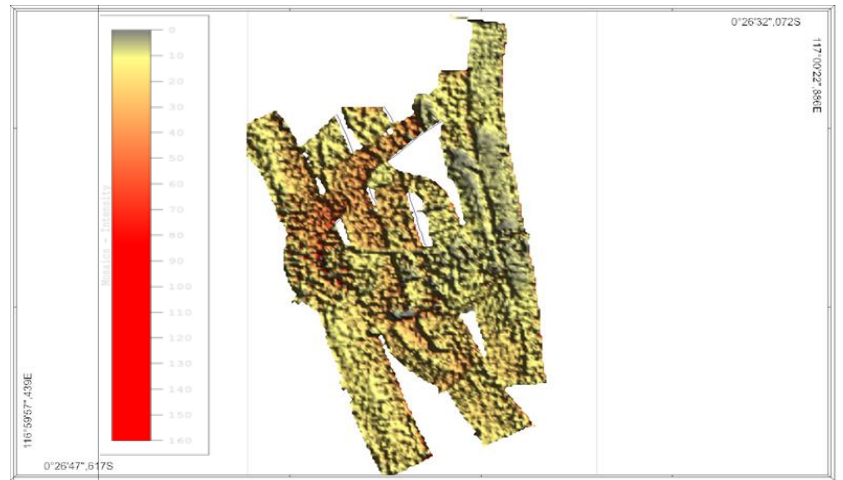

Figure 8. Mosaic of side scan sonar data

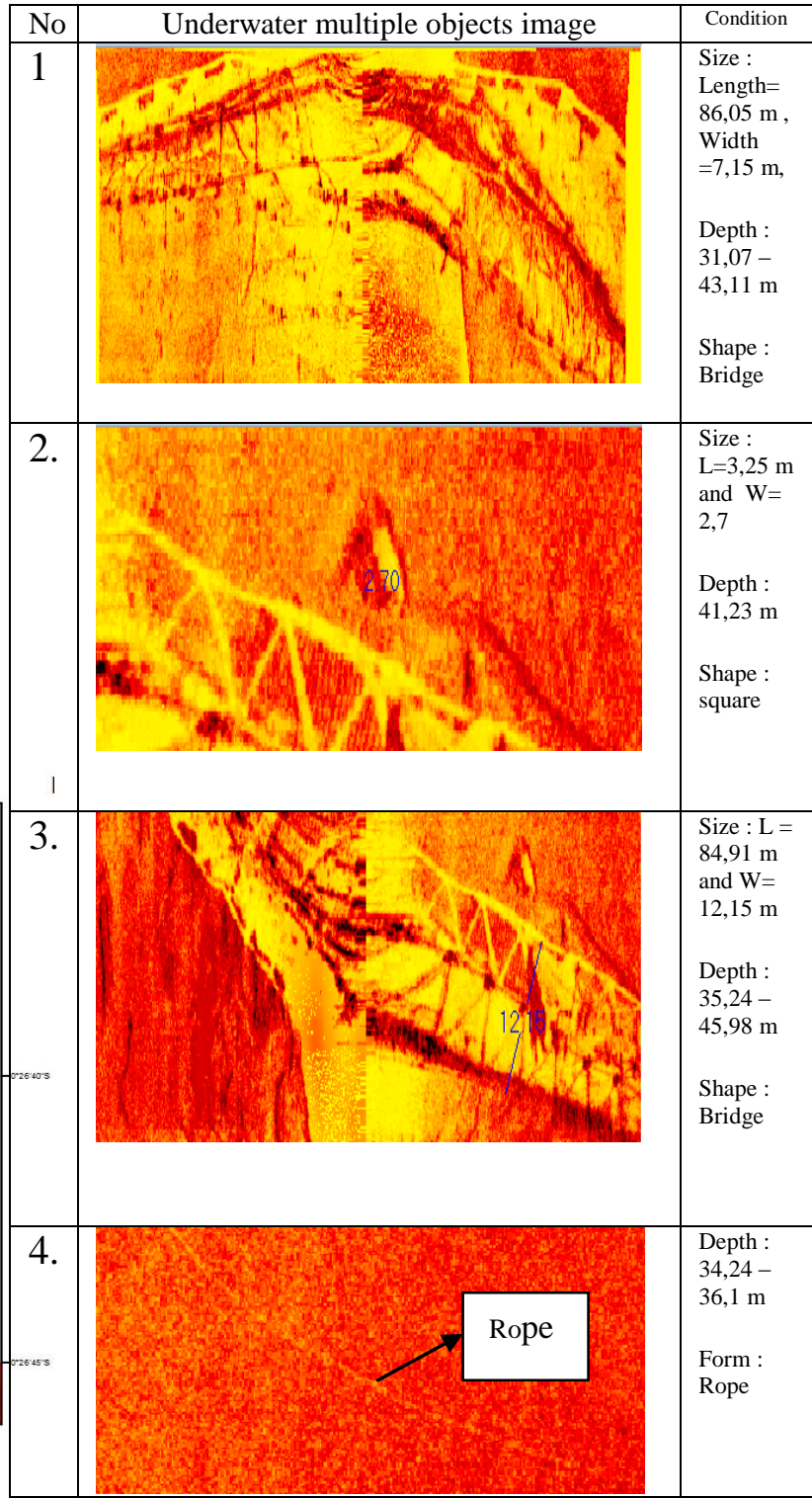

Figure 9. Underwater target detected using SSS

Results of Side Scan Sonar data processing has the various amplitude of underwater target. Highest amplitude value of the target is followed by a bridge-shaped, frame body, shape box / square, a small mound-shaped objects, objects strappy, rope, and bottom substrate (Table 1). 
Table 1. Range of underwater target amplitude using Side Scan Sonar

\begin{tabular}{|c|l|l|}
\hline No & $\begin{array}{c}\text { Underwater target } \\
\text { detected }\end{array}$ & $\begin{array}{l}\text { Amplitudo } \\
\text { range }(\mathrm{mV})\end{array}$ \\
\hline 1 & $\begin{array}{l}\text { Framework of the } \\
\text { bridge }\end{array}$ & $7200-7974$ \\
\hline 2 & A shaped box & $2019-2715$ \\
\hline 3 & Strap shaped & $1795-2490$ \\
\hline 4 & Small mound shaped & $819-830$ \\
\hline 5 & Rope & $684-729$ \\
\hline 6 & Bottom substrate & $258-454$ \\
\hline
\end{tabular}

In Table 1, the highest value of the amplitude of the target is found for the target framework of the bridge that is 7200-7974 $\mathrm{mV}$ and the lowest is the substrate with $258-454 \mathrm{mV}$. This is because the magnitude of the intensity of the reflection of sound from the ocean floor is generally dependent on the angle of the sound wave, the level of hardness (hardness), the level of roughness (roughness) seabed, seabed sediment composition, and sound frequencies used [11]. Sediment grain size has a greater reflection (backscattering) are more powerful anyway, sediment density (bulk density) will have a higher value greater backscattering [4]. Therefore, the harder objects in the sea bottom resulting the stronger of the reflection sound. Comparing with previous research [11]-[17], this value is nearly equal with our research By this research, underwater objects detection and tracking using Sonar instruments was possible.

\section{CONCLUSION}

Results of bathymetric data visualization shows the location of the research is a type of shallow water with a depth range of 4.07 meters to 58.15 meters. Results from side scan detection obtained frame bridge shaped, a shaped box / square target, strap shaped targets, small mound-shaped target, and the rope. Value of the intensity from the reflected sound waves are weakly from sea bottom, caused by the type of substrate constituent that dominates the bottom waters are mud. While the results of the calculation of the value estimate of the target amplitude found the highest values obtained are from the target frame bridge $(7200-7974 \mathrm{mV})$, followed by the target shape box / square $(2019-2715 \mathrm{mV})$, the target form a small mound (1795-2490 mV), the target strappy objects $(819-830 \mathrm{mV})$, the target shape strap $(684-729 \mathrm{mV})$, and lowest target forms a rope $(258-454 \mathrm{mV})$. The magnitude of the intensity from the reflected sound waves from the bottom of the water depending on the degree of hardness, roughness, and composition of marine sediments.

\section{ACKNOWLEDGMENTS}

The authors would like to thank Agency for Assessment and Application Technology (BPPT) Indonesia for data acquisition.

\section{REFERENCES}

[1] Hansen R E. 2011. Introduction to synthetic aperture sonar, in Sonar Systems. Edited by Nikolai Kolev. First Edition. InTech, Croatia. p.1-25.

[2] Medwin H and Clay C S. 1998. Fundamentals of Acoustical Oceanography. Academic Press. London.

[3] Bartholoma A. 2006. Acoustic bottom detection and seabed classification in the German Bight, Southern North Sea. Springer : Wilhelmshaven, Germany. Vol (26): $177-184$.

[4] Manik, H. M. 2011. Underwater Acoustic Detection and Signal Processing Near the Seabed, in Sonar Systems. Edited by Nikolai Kolev. First Edition. InTech, Croatia. Hal. : 255- 274.

[5] Tritech International Limited. 2008. Side Scan Sonar.

[6] CARIS. 2007. Caris Hips and Ships 6.1.1 User's Guide. 115 Waggoners Lane, Fredericton, New Brunswick, Canada, E3B 2L4.

[7] PDS 2000. 2011. PDS 2000 User Manual Version 4.0.0

[8] RESON B.V. Stuttgartstraat 42- 443047 AS Rotterdam The Netherlands.

[9] Mike K. 2008. Estimation of the ocean sound velocity profile.

[10] IHO. 1998. Special Publication 44. International Hydrography Bureau. Monaco.

[11] Urick R J. 1967. Principles of Underwater Sound for Engineers. Mc-Graw-Hill, New York, the United States of America.

[12] Anderson J T, D.V. Holliday, R. Kloser, D.G. Reid, and Y. Simrad. 2008. Acoustic Seabed Classification: Current Practice and Future Directions ICES J.Mar.Sci, 65: 1004-1011.

[13] Kågesten, G. 2008. Geological seafloor mapping with backscatter data from a multibeam echo sounder. Thesis. Department of Earth Sciences, Gothenburg University Box 460, SE- 405 30, Gothenburg, Sweden ISSN 14015765 .

[14] Collier, J. and Brown, C., 2005. Correlation of side scan backscatter with grain size distribution of surface seabed sediments. Marine Geology, 214, 4:15, 431-449.

[15] K. Foote, "Optimizing two targets for calibrating a broadband multibeam sonar," in OCEANS 2006, p. 1-4.

[16] E. Ona, V. Mazauric, and L. N. Andersen, "Calibration methods for two scientific multibeam systems," ICES J. Mar. Sci. 66, 1326-1334 (2009).

[17] B. Buelens, R. Williams, A. Sale, and T. Pauly, "Model inversion for midwater multibeam backscatter data analysis," in IEEE Oceans 05 Europe, 2005, pp. 431435 . 